\title{
Fisonomía de la resistencia en contra de las dictaduras del Cono Sur. Balances de una revisión historiográfica
}

Physiognomy of the resistance against the Dictatorships of the Southern Cone.

Balances of a historiographic review

Pedro VALDÉS NAVARRO

Pontificia Universidad Católica de Valparaíso, Chile

pedroalfonsovaldes@gmail.com

\section{Resumen}

El presente artículo tiene por objetivo revisar el panorama historiográfico en torno a las resistencias en contra de las Dictaduras militares del Cono Sur. El mapeo desarrollado persigue evidenciar los avances de las distintas historiografías locales, de tal forma de poder registrar lo que se ha escrito en torno a las diferentes formas militantes que buscaron oponerse a la anulación de la vida política, a partir de los golpes cívico militares de Paraguay, Brasil, Bolivia, Uruguay, Chile y Argentina. El comentario bibliográfico también nos permite observar los vacíos y los posibles espacios abiertos para nuevas perspectivas de estudio, no sólo en clave local, sino que también hacia una lectura continental y transnacional. Es factible evidenciar la existencia de una amplia gama de usos historiográficos en torno a la idea de resistir, lo que nos indica que estamos frente a la presencia de un concepto polisémico que abarca diferentes dimensiones históricas. Aun cuando los estudios sobre las resistencias no se han constituido como un campo articulado de estudio, sí creemos que los avances sistemáticos de las distintas historiografías locales pueden avanzar hacia la delineación de patrones comunes y visiones de conjunto.

Palabras clave: Historiografía; Resistencias; Dictaduras; Cono Sur.

1 Dr. (c) en Historia. Becario ANID.

Pedro VALDÉS NAVARRO

Fisonomía de la resistencia en contra de las dictaduras del Cono Sur. Balances de una revisión historiográfica

Sur y Tiempo. Revista de Historia de América, №4, julio-diciembre 2021, pp. 35-69.

ISSN 2452-574X

DOI: $10.22370 /$ syt.2021.4.2935 


\section{Abstract}

This article aims to review the historiographic panorama around the resistance against the military dictatorships of the Southern Cone. The developed mapping aims to show the advances of the different local historiographies, in order to record what has been written around the different militant forms that sought to oppose the annulment of political life, from the civic military coups of Paraguay, Brazil, Bolivia, Uruguay, Chile and Argentina. The bibliographic commentary also allows us to observe the gaps and possible open spaces for new study perspectives, not only in a local key, but also towards a continental and transnational reading. It is feasible to show the existence of a wide range of historiographic uses around the idea of resisting, which indicates that we are facing the presence of a polysemic concept that covers different historical dimensions. Although the studies on resistance have not been constituted as an articulated field of study, we do believe that the systematic advances of the different local historiographies, can advance towards the delineation of common patterns and visions of set.

Keywords: Historiography; Resistance; Dictatorships; Southern Cone.

\section{Introducción}

Es ampliamente observable el interés historiográfico que ha despertado la aparición de la lucha armada en el Cono Sur, a partir del triunfo de la Revolución Cubana, y con mayor énfasis en el accionar de las distintas orgánicas durante la larga década de los sesenta. Por otro lado, la instalación de regímenes dictatoriales a partir de diferentes golpes de estado protagonizados por las fuerzas armadas en su conjunto, también ha motivado un interés académico por conocer sus intenciones, identificar las etapas de estos gobiernos autoritarios, los vínculos con los EE.UU. y los detalles represivos en contra de la militancia y población civil. Sin embargo, observamos una debilidad en la relación existente entre el accionar de las izquierdas, por una parte, y la represión autoritaria frente a estas, por otra. En otras palabras, cómo resistió, no sólo la militancia, sino que otros sectores de la sociedad, a los embates de los dispositivos represivos, y cuál fue la naturaleza de esa resistencia. Esta dinámica es un tema todavía fértil para el debate.

El propósito de este panorama es observar cuáles han sido los enfoques de la historiografía para referirse al fenómeno de la resistencia en contra de las dictaduras militares del Cono Sur y determinar los acentos y junto con ello, los vacíos y los espacios menos explorados. Esta necesidad historiográfica nace del convencimiento de que es relevante detallar no solamente los pilares autoritarios en los cuales se anclaron los regímenes militares, o tampoco redundar en la victimización de la militancia, sino más bien resaltar el rol de la respuesta de la 
militancia y de la población afectada ante la instalación de esa represión autoritaria. Como todo ejercicio de revisión, existirán vacíos en la consideración final de cuales destacar. La omisión es un riesgo que vamos a cometer. Sin embargo, la intención es observar las diferentes expresiones de resistencia y acrecentar la visión heterogénea que sobre el concepto es necesario observar, más que la precisión sobre el catastro logrado.

Desde el punto de vista metodológico, la frontera que definimos abarcar está marcada por la instalación y durabilidad de las dictaduras del Cono Sur que se rigieron en distintos grados por la Doctrina de Seguridad Nacional y que comenzaron por el golpe militar de Brasil de 1964 hasta el golpe en Argentina de marzo de 1976. Dentro de estas experiencias autoritarias encontramos el caso de Bolivia en 1971, Uruguay en 1973 y Chile del mismo año. Si bien la dictadura de Alfredo Stroessner en Paraguay es anterior a este ciclo y más bien se vincula con las características de los regímenes personalistas de mediados del siglo, la sintonía que logró establecer durante la década de los setenta, sobre todo a través del Plan Cóndor, amerita su inclusión en esta revisión.

Uno de los primeros nudos que debemos resolver es qué entenderemos por resistencia. Si bien la acepción puede ser identificada con una actitud de desacato ante el orden establecido, la naturaleza misma de esa desobediencia es la que tiene importantes matices. Una primera idea que nos parece interesante exponer tiene relación con la delimitación del concepto mismo. Si bien una de las premisas de las ciencias sociales y disciplinas afines es la definición de un encuadre con el cual trabajar, la resistencia se rehúsa como concepto histórico a ser encasillada, convirtiéndose así en una idea que cobra fuerza por su praxis histórica. Tal como advierte Howard Caygill: "Una filosofía de resistencia tiene que resistir por sí misma la presión de la formación del concepto, de la reducción de las prácticas de resistencia a un único concepto dispuesto a la legitimación y apropiación por parte de la misma forma de Estado de la que empezó siendo un desafío (Caygill, 2016:22)”.

Para Caygill entonces, no existe una sola expresión de resistencia, entendida esta inicialmente como una respuesta contestataria a un orden impuesto desde arriba. Podemos hablar entonces de distintas formas de respuestas, de resistencias en plural y que se van articulando en torno a un sentir del deber de desobedecer frente a la opresión. Hay en juego no solamente un desafío ideológico, de choque de visiones políticas, sino que se configura una moral de resistencia que tal como señala Caygill, debe también impugnar el intento de apropiación del poder que comenzó contraviniendo.

Tomando en cuenta lo anterior, las formas que adoptó y de la cual los sujetos históricos que protagonizaron la resistencia en contra de las dictaduras del Cono Sur también se apropiaron como tal, fueron diversas y complejas, todas ellas necesarias de considerar a la hora de realizar un balance historiográfico, y ver cuál ha sido el 
recorrido investigativo sobre el fenómeno. Por cierto que este enriquecimiento del problema trae como consecuencia el ensanchamiento de los límites de su estudio, y por ende, una dificultad al momento de abarcar todo lo cognoscible. No obstante, para no desdibujar el nudo central y tomar en cuenta los resguardos de cualquier reflexión, es posible encontrar en las prácticas de resistencia de la militancia armada, de las acciones de sindicatos, de las protestas estudiantiles, de las expresiones artísticas y literarias de los presos políticos, de la insistencia en la labor informativa de los medios de comunicación opositores, como así también en el resguardo de la identidad cultural de las comunidades étnicas frente a la violencia explicita de los militares, una constante labor por impedir la anulación de su identidad política, eje central del accionar autoritario del período.

La desobediencia se expresa no solamente a través del componente armado, esta es una de las expresiones del accionar político, pero no la única. La militancia armada protagonizó una variante específica de lucha en contra de algunas dictaduras y se alimentó necesariamente de otras acciones no armadas, que forman parte del universo más amplio de desacato al autoritarismo. En las expresiones de sindicatos, universitarios, organizaciones civiles y otras orgánicas, se edificó una retórica moderada en donde se utilizó la idea de la violencia en contra de las dictaduras imperantes. No se invisibilizó de su horizonte textual, se entrelazó muchas veces con las acciones armadas, la identificación más clásica de la resistencia formó parte de un universo gris, de un eslabón invisible de oposición al autoritarismo.

Una tercera cuestión central, tiene que ver con el carácter histórico de la resistencia en relación a su continuidad temporal y la carga consiguiente de su significado. Rápidamente las oposiciones a las dictaduras del Cono Sur, conceptualizaron a estas como regímenes fascistas aliados con los monopolios foráneos. Esta categorización conllevó a elaborar una estrategia de enfrentamiento a través de un discurso y una acción, en donde la lucha antifascista conminaba a buscar las alianzas necesarias para conseguir la derrota. Se configuro así, una evocación histórica con las iniciales luchas en contra del avance del fascismo primero en España bajo el contexto de la Guerra Civil, y luego contra el nazismo alemán y el fascismo italiano durante la Segunda Guerra Mundial.

La izquierda a través de sus distintas expresiones, tanto contra Franco, luego contra Mussolini y Hitler, continuaban luchando contra el fascismo ahora bajo el contexto sudamericano, construyendo una utopía alcanzable de victoria, sobre todo en el caso del nazismo, convirtiendo a los partisanos en figuras heroicas y modelos de continuación guerrillera.

La ubicación de la militancia que luchó en contra de las dictaduras, en un sendero histórico de largo alcance, les adicionaba un mayor peso y sentido histórico 
a la empresa que estaban desarrollando, emulando muchas veces los ejemplos de las formas de lucha que adoptó la izquierda en contra del nazismo o del franquismo².

\section{Las resistencias del Cono Sur}

\subsection{La experiencia del Paraguay de Alfredo Stroessner}

Una de las constantes en la historia de la izquierda en América Latina durante el siglo XX, es el protagonismo y la presencia de los Partidos Comunistas como ejes articuladores del avance y desarrollo del movimiento de trabajadores. Si bien ese protagonismo se dio con diferentes matices, en todos los países recogidos como experiencias de resistencias antidictadoriales, los comunistas tienen algún grado de incidencia en la forma que se dio la conducción de este proceso.

No obstante, a medida que diversos fenómenos transnacionales iban afectando las realidades locales, el concierto de diversificación de la izquierda, generó un panorama variopinto de herederos y reivindicadores del marxismo. Esta heterogeneidad en el continente produjo una respuesta también diversa en torno al tipo de enfrentamiento y resistencia antidictatorial. Para el caso paraguayo, la experiencia autoritaria más extensa del Cono Sur, la disruptiva vida democrática antecesora del gobierno de Alfredo Stroessner generó una aclimatación, no sólo del PC paraguayo, sino que del conjunto del movimiento de trabajadores, a la persecución y la clandestinidad. Esto devino en una temprana respuesta armada a la implantación del gobierno de Stroessner. Una de las revisiones más completas de este inicial proceso, es "La resistencia armada a la dictadura de Stroessner", publicada por la revista NovaPolis. Este especial de la revista, se enfoca en describir las facetas que tuvo la larga y variada oposición a Stroessner, entregando a través de la revisión de documentos, fuentes orales, artículos y libros, un panorama detallado de quienes y en qué momentos, fueron los protagonistas de este periodo. Al abarcar una temporalidad extensa e intentar cubrir la mayor cantidad de experiencias, quedan espacios menos explorados como son el rol de género en dicha resistencia, las alianzas con otras fuerzas opositoras, o la intimidad de las orgánicas clandestinas, pero, sin embargo, el enfoque permite realizar una evaluación del proceso más allá del levantamiento de los mitos y mártires propios de estos enfoques. En este sentido podemos rescatar lo que señala Andrew Nickson:

\footnotetext{
2 María Florencia Osuna (2015) menciona, por ejemplo, que varios militantes de organizaciones de la izquierda argentina buscaron referencias literarias para emular situaciones de lucha en contra de la represión, tal fue el caso del libro de Gilles Perrault "La orquesta roja", relato que narra la experiencia de la red de espionaje clandestino soviético en contra de la Alemania Nazi. Este ejemplo es referenciado también por Anna Blasco Rovira y Vladimir Sierpe (2015) en su investigación sobre la clandestinidad del PS de Chile.
} 
En resumen, al mirar hacia atrás, sería muy fácil criticar el fracaso de estos intentos de lucha armada contra el régimen de Stroessner. Sin embargo, sería injusto atribuir este fracaso a la locura de individuos egocéntricos, o al aventurismo político por partes de unos ingenuos, o a un intento muy simplista de copiar la revolución cubana o la resistencia al gobierno militar en Argentina. Estos movimientos surgieron como respuesta a circunstancias históricas específicas, tanto en términos nacionales como internacionales (Nickson, 2004: 39).

Dentro del mismo escenario paraguayo, destaca la indagación sobre la resistencia cotidiana de un grupo de indígenas del este del país, los Aché y de cómo ciertas prácticas culturales y sociales, también se convierten en formas de resistir. La investigación referida es "La resistencia cotidiana de los Aché durante el régimen cívico-militar de Alfredo Stroessner en el Paraguay”, de Paulo Alves Pereira, que tiene el mérito de rescatar a sujetos históricos relegados en distintos momentos de la historia americana, para dar cuenta del protagonismo político en circunstancias que ese rol se le asigna mayoritariamente a militantes, estudiantes, obreros e intelectuales. Según el autor, ante al autoritarismo estatal, muchos Aché resistieron al stronismo de distintas maneras:

A través de Asambleas Indígenas reivindicaron sus derechos territoriales y la valorización de sus culturas y de sus organizaciones socioeconómicas. Contando con el apoyo de determinados sectores de la prensa escrita nacional, de grupos político-sociales y de intelectuales, diversas comunidades que antes eran rivales pasaron a luchar contra un único enemigo: el régimen de Stroessner (Alves, 2017: 118).

Mediante la revisión de artículos, libros y documentación, el autor expande el universo de las lógicas de resistencia más clásicas para el período y aporta una visión cotidiana y minimalista de prácticas opositoras al autoritarismo, llevándolo al espacio de la intimidad de las comunidades indígenas.

Bajo el interés de buscar revitalizar una historiografía más tradicional en sus perspectivas analíticas, el trabajo de Alfredo Boccia, "Represión política y género en la dictadura paraguaya" apunta a engrosar los trabajos sobre militancia femenina durante las últimas dictaduras. En un enfoque reivindicativo del rol en la construcción de una resistencia más amplia a la dictadura paraguaya, el trabajo de Boccia recoge a través de documentación y fuentes secundarias, la doble dificultad que tuvieron que enfrentar las mujeres en contra del régimen de Stroessner. Por una parte, fueron objeto de las más duras acciones represivas de corte sexual, en un contexto social e histórico que se acostumbró e invisibilizó las prácticas abusivas en 
contra de mujeres. Y, por otro lado, como menciona el autor, "las mujeres que resistieron activamente a la dictadura, fueron parte de aquellas que no siguieron el curso normal y esperable de sus historias. Rompieron con lo establecido y fueron protagonistas, aunque para eso debieron meterse en asuntos 'de hombres" (Boccia, 2010: 80).

Boccia recoge el rol organizativo de mujeres campesinas y de las ciudades a través de la constante generación de instancias de coordinación como fueron la Coordinación de Mujeres Campesinas, Mujeres por la Democracia y el Primer Encuentro Nacional de Mujeres que llevó a la concreción de la Coordinación de Mujeres del Paraguay.

\subsection{La larga dictadura brasileña}

Brasil inaugura una forma particular de instalación de régimen represor no sólo en la arquitectura que moldeó inicialmente el general Castelo Branco, sino también, desde sus escuelas castrenses nacerían los enfoques sustentadores de la lucha en contra del comunismo. Junto con lo anterior, es posible comenzar a delinear las variantes de la resistencia que se encumbraron en contra de la rotativa militar que gobernó desde 1964 hasta 1985.

A diferencia del caso paraguayo, el grado de desarrollo industrial y económico del Brasil, potenció la existencia de un movimiento obrero más poderoso y numeroso, lo que posibilitó, además, la existencia de un Partido Comunista más protagónico en el liderazgo de los trabajadores. No obstante, al igual que la dictadura de Stroessner, la duración de este ejemplo autoritario nos permite abarcar su examen a través de distintas etapas y con la presencia heterogénea de diversas resistencias. Quizás el estudio más acabado en estos dos sentidos, es el trabajo de Inés Nercesián, "Una aproximación a la izquierda brasileña de los años sesenta. Partidos y organizaciones armadas". La autora categoriza y caracteriza la aplicación de la represión en distintos momentos, lo que tiene como respuesta la estructuración de diversas resistencias. Nercesián señala:

Es decir, mientras que las primeras actas institucionales se destinaban a clausurar la esfera de acción política de todas las organizaciones civiles... a partir del AI 5 (Acto Institucional) se terminaba de montar el aparato represivo que abría las puertas para la supresión más violenta de las libertades civiles. A partir de aquí, la represión iba a ser especialmente dura, sobre todo para las organizaciones armadas más radicales, e implicó en casi todos los casos, su disolución (Nercesián, 2005: 31). 
En este sentido, un primer instante de máxima represión y, por ende, de mayor profundidad de la resistencia militante se produce durante los primeros años dictatoriales y expresados esta, en la implementación de organizaciones armadas todas ellas muy influenciadas por el foco rural.

Situación aparte merece el estudio del comportamiento del Partido Comunista de Brasil, que al igual que otros de la región, decidió adoptar una posición intermedia y dubitativa en torno a la oposición al régimen dictatorial. Nercesián detalla la disputa entre Luis Carlos Prestes y Carlos Marighella, en torno al camino opositor a definir. Para este último, la opción era la resistencia armada, situación que decantó en la división orgánica.

Otro de los sujetos preponderantes de la militancia brasileña fue el sector campesino, que, por las características del espacio geográfico del Brasil, jugó un rol activo en la defensa de sus intereses colectivos. Una trama interesante es indagar en las motivaciones de éstos a la hora de emprender un enfrentamiento directo en contra de la dictadura. Fabricio Telo en "Campesinos, emociones y tentativas de resistencia armada a la dictadura empresarial-militar de Brasil", se interna en un camino íntimo de análisis de los motores para concretar el desafío del derrocamiento armado. El autor comenta que

...el objetivo de este artículo es analizar el impacto de las emociones en esas relaciones entre militantes de organizaciones guerrilleras y campesinos sin experiencia previa en la lucha armada... ¿Quién es, entonces, el que habla al campesino y qué es lo que comunican, lo que mueve al campesino a la acción política violenta? Los campesinos albergan un profundo sentido de injusticia, pero a este sentido de injusticia se le debe dar forma y expresión en la organización antes de que pueda activarse en la escena política (Telo, 2019: 13)

Tomando como referencia el estudio de la emocionalidad en los campesinos de El Salvador y su integración en la guerrilla, el trabajo desarrollado por Elizabeth Jean Wood "The Emotional Benefits of Insurgency in El Salvador", sirve de referencia para Telo, que lo aplica también para el caso brasileño. El autor sostiene: “...los beneficios emocionales (por ejemplo, la alegría y el orgullo) consecuencia de la implicación en la lucha eran muchas veces más importantes que ciertos beneficios materiales, como el acceso a la tierra o más derechos. La lucha en sí misma era fuente de dignidad y respecto" (Telo, 2019: 2).

Aunque es una tesis doctoral y no un texto publicado, nos parece una aproximación muy interesante y nos permite mantener esta idea inicial de recoger el amplio espectro de la noción de resistencia. La autora Marcia Guena Dos Santos trabajó en 2014 a los Afro-brasileños en lucha: historia de la resistencia negra a la dictadura militar en Brasil (1964-1985). Para Dos Santos, la participación de 
militantes afrodescendientes en determinadas organizaciones clandestinas que lucharon en contra de la dictadura, fue una acción mayoritariamente en orgánicas pertenecientes a la nueva izquierda, ya que los partidos tradicionales marxistas, tenían una visión más conservadora sobre los “sujetos revolucionarios”. El estudio se interesa en recoger las variables étnico-raciales, de un conflicto político que atravesó el continente, mostrando como es el caso, las particularidades y complejidades propias de una sociedad que no resolvió determinadas temáticas, apareciendo estas de modo subterráneas en contexto de presión y sobrevivencia.

También pueden considerarse como estudios de interés: "As oposições à ditadura: resistência e integração" de Marcelo Ridenti; y A Mulher que era o general da Casa. Histórias da resistência civil á ditadura, de Paulo Moreira Leite. En una profundización sobre la resistencia de género en un contexto conservador y represivo, puede verse el trabajo de James N. Green y Renan Quinalha, Ditadura e Homossexualidades: Repressão, Resistência e a busca da Verdade. Sobre el rol de la cultura en la lucha por la libertad de expresión, ver, Censura, Imprensa, Estado Autoritário (1968-1978) de María Aparecida Aquino; y Desmistificando a "Resistência democrática" a ditadura civil-militar (1964-1985) de Natanael de Freitas Silva. En una apuesta similar a la investigación de Marcia Guena dos Santos sobre el rol resistente de las comunidades afrodescendientes, puede revisarse, de Ana Laura Horbach, Autoria e resitencia negra na ditadura civil-militar no Brasil.

\subsection{Del histórico movimiento obrero boliviano, a la resistencia estudiantil en contra de Banzer. El balance historiográfico en Bolivia}

Como en varios ejemplos anteriores, la oposición de un sector considerable de la población a las políticas aplicadas por distintos gobiernos de carácter capitalista, sumada a la ancestral visión de la posición de explotados, conformó una presencia latente del movimiento obrero, en particular de los sectores mineros. A lo anterior, la maduración de los sectores campesinos de la década de los sesenta, y la masificación de un sujeto universitario cada vez más empoderado, aglutinó un componente opositor a los distintos gobiernos autoritarios. Con la irrupción de la dictadura de Hugo Banzer en 1971, mineros, campesinos y universitarios, van a conformar el principal movimiento de resistencia.

Dentro de los avances historiográficos destacados en ese ámbito podemos considerar el trabajo de Lawrence Whitehead, "Sobre el radicalismo de los trabajadores mineros de Bolivia", quien recalca el rol de los mineros en el derrocamiento de la dictadura de Banzer, pero sobre todo en su afán como movimiento de lucha en pos de la autonomía sindical, la determinación de defender sus salarios, sus condiciones de vida. La fuerza de este sector radica en su asombrosa capacidad "para soportar la represión y continuar insistiendo con sus 
demandas básicas, superando fácilmente en este respecto a la mayoría de los partidos políticos bolivianos. Este articulo ha identificado el carácter solidario de las organizaciones sindicales locales como un factor esencial para este tipo de logros..." (Whitehead, 1980: 1495).

Como en casos anteriores, el fin de los regímenes autoritarios estimuló el desarrollo más constante de diversas apuestas historiográficas. De 1980 se destaca la voluminosa obra de Guillermo Lora sobre el movimiento obrero boliviano. En el IV tomo, el dirigente trotskista repasa en un relato testimonial los detalles de la primera resistencia a la asonada gorila de Banzer, y las actuaciones de sindicatos y estudiantes. En Historia del movimiento obrero boliviano. El proletariado en el proceso político, 1952-1980, Lora describe el panorama más íntimo de la nueva etapa de sobrevivencia.

En Bolivia era inconcebible la reunión pública de un partido obrero o simplemente democratizante; incluso en 1977 sólo podían efectuarse pequeñas y rápidas reuniones políticas en la clandestinidad. La plana mayor revolucionaria estaba en las cárceles, en el exilio o llevando vida subterránea. Ningún izquierdista podía hacer política en el Prado de La Paz, cosa habitual en el pasado (Lora, 1980: 154).

En una similar descripción, del mismo autor, su trabajo sobre el Partido Obrero Revolucionario, el POR, Lora destaca el papel jugado por esta organización trotskista y por el resto de la izquierda, en crear los primeros núcleos de la resistencia que tuvo como gran componente de fuerza, la unidad no sólo política, sino que también militar de las organizaciones antifascistas. Lora en Historia del POR. Contribución a la Historia política de Bolivia, destaca la lucha del partido durante la dictadura, en distintos espacios, ampliando la lógica del accionar meramente partidista. Lora comenta: "No era cuestión de denunciar únicamente los atropellos gubernamentales y patronales, sino de orientar y dirigir políticamente a los trabajadores y a las vastas capas de la clase media, por esto se imponía aprobar y divulgar un programa de principios, pese a que ya existían las Bases Constitutivas" (Lora, 1978: 250).

En otro de los ejes de análisis sobre la resistencia boliviana, resalta el rol del indigenismo, también como actor constante de respuesta contestataria frente a la opresión, intensificada durante los momentos dictatoriales. En la obra de Silvia Rivera Cusicanqui, Oprimidos pero no vencidos. Luchas del campesinado aymará y quechwa 1900-1980, la autora analiza la constante presencia del movimiento campesino-indígena durante el lapsus de persecución, cárcel y exilio, actuando en la clandestinidad y siendo la barrera de contención, además, de las intenciones políticas que buscaban una reorganización social, sobre todo del movimiento indígena. Es en este contexto que surge el Katarismo como expresión de articulación 
política de una demanda concreta desde el mundo indígena. Rivera Cusicanqui comenta:

Durante el año 1976 los kataristas se hicieron presentes en varios eventos universitarios y obreros como representantes de la nueva tendencia reivindicativa del campesinado indio... La represión se extiende no sólo a los dirigentes del Centro Tupaq Katari que actuaban en la clandestinidad, sino a los líderes sindicales que habían logrado incrustarse en el aparato sindical oficialista (Rivera, 2010: 190).

Es con este tenor de constancia y atrevimiento directo, que la persistencia de un movimiento de resistencia indígena no sólo tenía relación con cuestiones culturales, sino que representó, además, un soporte político para el derrocamiento de la dictadura de Banzer.

Suerte dispar correrían los militantes del Ejército de Liberación Nacional boliviano, quienes se destacaron protagonizando una de las acciones de resistencia más espectaculares en contra de todos los golpes del Cono Sur, cuando un contingente fuertemente armado del ELN decidió evitar el golpe en contra del general Juan José Torres. El análisis de este evento, y lo que ocurriría después con esta organización y su intención de resistir, es parte de los distintos análisis que el historiador Gustavo Rodríguez Ostria ha hecho sobre el tema. En “Guerrilla, armas y campesinado: del Ejército de Liberación Nacional (ELN) al Partido Revolucionario de los Trabajadores en Bolivia (PRTB) (1967-1977)", se relata la lenta caída en manos de la represión boliviana y también chilena y argentina, de los integrantes de la organización heredera del Che Guevara, y cómo sus intentos de mantener con vida a la estructura se superponen al intento por mantener la vida de sus militantes. El dramático y crítico escenario, es descrito por Rodríguez Ostria:

Entre fines de mayo y junio de ese año (1972), al menos una docena de sus militantes más importantes fueron asesinados en distintas cárceles o en lugares de detención. En los meses sucesivos las capturas continuaron, incluyendo a un grupo de chilenos que llegó a Bolivia para reforzar las actividades del golpeado ELN. La organización quedó prácticamente desmantelada" (Rodríguez Ostria, 2017: 194).

Sobre las luchas estudiantiles puede revisarse el trabajo de Juan Marcelo Verdueta, "El Movimiento Universitario frente a la dictadura en Bolivia. El caso de San Andrés del 71", que indaga en el rol jugado por los universitarios durante la dictadura, y en la brutal represión sufrida por este sector. El autor recalca que la resistencia en contra de la dictadura de Banzer fue un proceso que se venía germinando desde mediados de los años sesenta, y que la desobediencia surgida en contra de la dictadura, a pesar de los duros golpes represivos, fue un eje articulador 
de la identidad de estos universitarios. El influjo del proyecto revolucionario guevarista conformó un movimiento universitario de izquierda y con sólidas convicciones socialistas, lo que se mantuvo durante el período autoritario, posibilitando la permanencia y constante renovación militante durante los años más oscuros del banzerismo.

\subsection{La oscuridad en la Suiza de América del Sur. El golpe en Uruguay}

Luego del golpe militar de Banzer en Bolivia, la escalada autoritaria asomó hacia los países más australes de la zona: Uruguay, Chile y Argentina. Casi con una sincronía defensiva de la amenaza roja, estos últimos ejemplos representaron también las muestras de la coordinación más peligrosa para la izquierda del continente.

En el caso uruguayo, la aparición desde fines de los sesenta de una izquierda revolucionaria que trastocó el panorama político del Uruguay se convirtió años más tarde en uno de los principales focos de estudio historiográfico. La presencia del Movimiento de Liberación Nacional Tupamaros en una sociedad que aparecía como un ejemplo de civilidad, vino a poner sobre el debate la discusión sobre las formas de hacer política y los caminos de la transformación social. Por otra parte, y desde un plano más orgánico, la adaptación guerrillera del ejemplo cubano al espacio urbano de Montevideo, generó un interés particular sobre la doctrina revolucionaria misma. Referentes importantes sobre el MLN-T son: La Historia de los tupamaros (3 volúmenes) de Eleuterio Fernández Huidobro; La Guerrilla tupamara, de María Esther Gilio; Historias tupamaras. Nuevos testimonios sobre los mitos del MLN, de Leonardo Haberkorn; La revolución imposible. Los Tupamaros y el fracaso de la vía armada en el siglo XX, de Alfonso Lessa; Antecedentes ideológicos del Movimiento de Liberación Nacional (Tupamaros) de Paula Peña Hasbún; y Una historia de los Tupamaros: de Sendic a Mujica de Alain Labrousse, entre otros. Sin embargo, paradojalmente, y tal como ocurre con el caso argentino, la detención y profundización sobre el fenómeno guerrillero, estuvo puesta mayoritariamente en el actuar bajo el contexto pre dictatorial, es decir antes de marzo de 1973, quedando en un rango de análisis secundario, la experiencia de resistencia durante la dictadura. Tal como veremos en las apreciaciones de los que han estudiado el tema, el desgaste previo en términos de la intensidad de la acción política de estas orgánicas, les restó fuerza al comenzar la dictadura uruguaya, llegando absolutamente disminuidos en su capacidad orgánica y militante, por lo que, en gran medida, la acción política más recurrente fue la salida al extranjero, para desde allí intentar reestructurar a los alicaídos Tupamaros.

La revisión de la izquierda uruguaya que resistió puede examinarse en el trabajo de Vicent Galiana I Cano, en "El triunfo del posibilismo: el MLN-Tupamaros 
entre la revolución armada y la integración democrática (1970-1989)”, que revisa cuantitativamente las consecuencias de la represión entregando un panorama crudo y empírico del desarme. Así, Galiana cuenta en cerca de mil los tupamaros encarcelados, junto con unos cientos viviendo en la clandestinidad y otros cientos de miles exiliados ya tempranamente en Chile, Cuba, Argentina y Europa.

Uno de los estudios más acabados sobre esta orgánica político-militar, es el trabajo de Clara Aldrigui, La izquierda armada. Ideología, ética e identidad en el MLNTupamaros. Tal como sostiene la autora y otros investigadores, la situación de Uruguay en términos de la estabilidad política e institucional, venía fisurándose ya desde fines de los sesenta y principios de los setenta. La incorporación paulatina de los militares al gobierno civil y con ello la instalación de un estado policial, dispuso de un modus operandi, en donde la suspensión de las garantías individuales junto con la persecución, el encarcelamiento y la tortura hacia la militancia de izquierda, fueron parte del nuevo escenario represivo. En ese sentido, los Tupamaros comenzaron desde temprano su accionar resistente en contra de las disposiciones del régimen, previo a la institucionalización del gobierno autoritario de Bordaberry. Ya con la suspensión de la vida política a partir de junio de 1973, los Tupamaros se sumergieron en la clandestinidad con un nivel de desgaste orgánico y militante, que se arrastraba desde dos años antes de 1973. Así, si bien el estudio de Aldrigui se sumerge en distintas dimensiones del actuar tupamaro, la debilidad en el trato durante el período 1973-1985, deja varias interrogantes en torno al accionar durante la dictadura. También de Aldrighi, Memorias de insurgencia: historias de vida y militancia en el MLN-Tupamaros 1965-1975, se centra no solamente en la lucha local de los Tupamaros en contra de la dictadura, sino que también ofrece una mirada a los rasgos internacionalistas de la identidad que la organización comenzó a delinear. Así, el escenario de resistencia se amplía, como parte de un objetivo de mayor rango: la lucha por la liberación del continente, y la búsqueda de coordinaciones transnacionales revolucionarias. En otro estudio sobre el tema, la resistencia dentro de un plano testimonial aparece reflejada en el libro de Hugo Cores, Memoria de la Resistencia, o el interesante planteamiento de la labor reconstructiva a través del plano cultural, en Trincheras de papel. Dictadura y literatura carcelaria en Uruguay de Alfredo Alzugarat. Este último comenta;

Sin embargo, en veinte años a esta parte, poco se ha insistido en la resistencia cultural que afortunadamente existió; en la osada respuesta, constructiva y colectiva, paciente y eficazmente forjada en esas cárceles, es decir, en el vientre mismo del enemigo. Resistencia y respuesta que abarcaron muchos ámbitos del saber y del quehacer, abierta a la amplísima gama de cuanto podemos reconocer como cultura de salvación (Alzugarat, 2007:5) 
Dentro de la misma esfera, y uno de los primeros intentos de recrear la cotidianeidad uruguaya en contextos autoritarios, se inscribe la compilación de Saúl Sosnowski, Represión, exilio y democracia: La cultura uruguaya. Estas reflexiones surgieron en 1986, bajo el contexto de un encuentro intelectual, entre quienes estaban Eduardo Galeano, Leo Masliah, Mauricio Rosencof, entre otros. En estas miradas aparecen las escenas de la música popular y la censura, el silencio, los imaginarios sociales, los partidos políticos y la vuelta a la democracia, entre otros. Importante es también la compilación documentada de Alcira Legaspi de Arismendi, en La resistencia a la dictadura. 1973-1975. Tomo I Cronología documentada. Contribución a la memoria popular sobre la historia reciente del Uruguay, que es un esfuerzo temprano no sólo por describir las acciones, sino también por dilucidar tareas que en muchas ocasiones aparecen en un horizonte nebuloso para la ciudadanía.

\subsection{El duro golpe al sueño de la vía chilena al socialismo}

Con notables diferencias en relación a las características con que se dio en el resto de las experiencias del continente, en el caso chileno, se puede hablar y examinar una resistencia asentada y con múltiples expresiones, sólo a partir de la instalación del régimen dictatorial de Augusto Pinochet, entre septiembre de 1973 y marzo de 1990. Antes, la estabilidad del régimen democrático y la participación en el sistema partidista de los dos grandes partidos de la izquierda dejó en un protagonismo marginal a aquellas expresiones antisistémicas. Al pretender eliminar toda acción política del escenario nacional, la junta militar decretó la prohibición de toda organización partidista, encontrando los opositores al régimen, distintas formas de subvertir el orden impuesto, observándose estas señales de vida de manera más visible luego de la primera etapa de máxima represión, a partir de 1977/1978.

El Movimiento de Izquierda Revolucionario, MIR, fue posiblemente uno de los primeros objetivos de búsqueda, por lo que la represión inicial entre septiembre de 1973 y octubre de 1974 fue la más brutal y terminante. Análisis de estas señales de resistencia y las posteriores desde fines de los setenta y con mayor contundencia entre comienzos de los años ochenta, pueden verse en la descripción de Andrés Vera Quiroz en, Tortura, clandestinidad y dictadura. Una mirada desde la militancia mirista, 1982-1984. En un acto de justicia, de lucha contra la amnesia y como el mismo autor relata, en contra de la desaparición de la memoria, Eduardo Arancibia Ortiz en Las milicias de la resistencia popular. El MIR y la lucha social armada en dictadura, recalca no sólo las acciones y pretende con esto evidenciar la visibilidad del acto de resistencia, sino que además intenta demostrar la conexión con el movimiento popular que desde comienzos de los años ochenta estaba iniciando su rearticulación. Estos acercamientos, como otros, son miradas militantes que buscan 
insertarse en la historia a través del rescate de la memoria de un período oscuro y subterráneo. Desde otros planos, la historiografía nacional se ha dedicado con un marcado acento a analizar el rol jugado por el MIR durante dichos años. Podemos destacar el libro de Igor Goicovic Donoso, Trabajadores al poder. El Movimiento de Izquierda Revolucionaria (MIR) y el proyecto revolucionario en Chile. Goicovic plantea que, para el período en estudio, el mirismo rápidamente asimiló su estructura partidaria al contexto que se abría, de mejor manera incluso que comunistas y socialistas. El autor recalca: "Para poder desarrollar esta línea de intervención estratégica era imprescindible abordar una serie de objetivos preliminares: fortalecer y acerar el partido, reconstruir la FSR y dar origen al Ejército Revolucionario del Pueblo (ERP) para, a partir de ello, derrocar a la Dictadura y conquistas el poder" (Goicovic, 2016: 123).

De similares características pueden encontrarse también los trabajos de José Antonio Palma, El MIR y su opción por la guerra popular, y la investigación de Mario Amorós, La memoria rebelde. Testimonios sobre el exterminio del MIR de Pisagua a Malloco. Robinson Silva Hidalgo, plantea en Resistentes y Clandestinos. La violencia política del MIR en la dictadura profunda, 1978-1982, que hay que entender que la violencia política y el movimiento social antidictatorial surgen en conjunto y motivados por una estrategia planificada desde los sectores radicales como forma de respuesta a la dictadura. En este sentido, comenta Silva, “...es en los sectores populares donde se centró la participación de la Resistencia, a través de múltiples actos de violencia de baja intensidad, ligados a las movilizaciones sociales donde se articuló una forma de protesta radicalizada, convocando al posicionamiento político de los pobres urbanos" (Silva, 2011: 89).

Finalmente, también es pertinente examinar principalmente el capítulo 4 de Sergio Salinas, El Tres Letras. Historia y contexto del Movimiento de Izquierda Revolucionaria, y de Cristian Pérez, "Historia del MIR. Si quieren guerra, guerra tendrán".

La resistencia protagonizada por el Partido Comunista ${ }^{3}$ durante el período se funda en algunos espacios temporales con las acciones perpetradas por el Frente Patriótico Manuel Rodríguez, FPMR. Si bien el alcance y el impacto causado por uno y por otro es muy disímil, la persistencia de los dirigentes y militantes del comunismo chileno de mantener con vida al partido en un primer momento de máxima represión, nos permite rastrear desde muy temprano la existencia de una resistencia pasiva a la dictadura. En este marco, los trabajos del historiador Rolando Álvarez son muy relevantes. En Desde las sombras. Una Historia de la clandestinidad comunista (1973-1980) el autor señala en referencia a la idea de resistencia que:

${ }_{3}$ Sobre este tema existen dos balances historiográficos sobre los partidos de izquierda que merecen la atención: Rojas Flores (2000) y Álvarez (2017). 
La relación entre la realidad de la vida cotidiana impuesta por la racionalidad del terror dictatorial, la cultura del miedo generada por este y la aparición desde un momento muy temprano de una subjetividad de la resistencia entre los militantes de izquierda y, por ende, entre los viejos y jóvenes comunistas chilenos, fue el embrión desde ronde iban a incubarse unos nuevos modos de hacer y de vivir la política partidaria, que cristalizarían en los años ochenta con la política de rebelión popular (Álvarez, 2003: 12).

Es decir, la actividad clandestina de resistencia aparece marcada por experiencias previas y por convicciones que son parte de un acervo valórico e ideológico, que mantienen la vida del partido y de sus militantes, aun al borde de la extinción. Similares trabajos del autor pueden revisarse, por ejemplo, Rolando Álvarez, Arriba los pobres del mundo. Cultura e identidad política del Partido Comunista de Chile entre democracia y dictadura. 1965-1990; "Las Juventudes Comunistas de Chile y el movimiento estudiantil secundario: un caso de radicalización política de masas (1983-1988)" o “Clandestinos 1973-1990. Entre prohibiciones públicas y resistencias privadas”. De Viviana Bravo Vargas, ¡Con la razón y la fuerza, venceremos! La rebelión popular y la subjetividad comunista en los '80. La autora sostiene:

La tónica hasta fines de 1976 fue esa, intentar sobrevivir, primero, físicamente, y luego, creando pequeños vínculos para la sobrevivencia orgánica. Tiempos de aprender a moverse en clandestinidad, de aprender de los errores y esquivar al enemigo, de reafirmar vínculos solidarios, de constatar el dolor de la traición y la desconfianza que viene por añadidura Desde 1973 hasta 1976, fueron años en que la militancia aprendió a implementar normas de seguridad en su experiencia cotidiana. Es una etapa marcada por la tristeza, el miedo, la espera del fin de días aciagos que no terminaban jamás (Bravo, 2010: 163).

Cruzados entre la delgada línea que separó la formación de una política de enfrentamiento en contra de la dictadura y la creación del FPMR, se encuentran los trabajos de Claudio Pérez, "La Política de Rebelión Popular de Masas y el Movimiento Democrático Popular (MDP): Una mirada a la política de alianzas del Partido Comunista de Chile bajo Pinochet, 1980-1988”. De la rebelión popular a la sublevación imaginada de Luis Rojas Núñez y, Carrizal. Las armas del PC, un recodo en el camino, del mismo autor. Sobre el FPMR propiamente tal: Frente Patriótico Manuel Rodríguez. El Tabú del conflicto armado en Chile de Hernán Vidal, o los pasajes de la preparación y ejecución del atentado contra Pinochet: Los fusileros, de 
Juan Cristóbal Peña. Completan esta parte de los testimonios y experiencias en el frente, el relato de Mauricio Hernández Norambuena, Un paso al frente. Habla el comandante Ramiro del FPMR. En un formato novelado, José Miguel Carrera nos cuenta las experiencias de jóvenes militantes comunistas que se entrenaron en Cuba, lucharon en Nicaragua y se prepararon para combatir a la dictadura de Pinochet: Somos tranquilos pero nunca tanto... De Tito Tricot, Un sociólogo en el FPMR, y Juan Soto Vergara, El FPMR y el batallón 7, se pueden apreciar en testimonios de primera fuente, sus experiencias en las luchas antidictatoriales como pertenecientes del Frente, actuando en distintos espacios de acción, desde el trabajo poblacional, hasta las tareas de solidaridad e inteligencia en el extranjero.

Para el caso del MAPU, un análisis profundo de la transformación política desde el plano ideológico puede verse en el trabajo de Cristina Moyano, El MAPU durante la dictadura. Saberes y prácticas políticas para una microhistoria de la renovación socialista en Chile 1973-1989. Si bien el foco principal de la investigación de Moyano está en identificar las bases de la transformación política desde la revolución a la renovación, en relación al primer momento de reorganización de la colectividad que implicaba tácitamente la aceptación de la resistencia como base para desarrollar cualquier enfoque político a futuro, el MAPU destacó inicialmente que:

Tal como manifestaran un poco más tarde los documentos de los intelectuales, sería desde la propia cotidianeidad, desde los propios conflictos pequeños y presentes en el día a día, como lo eran la cesantía, el hambre y la falta de libertades, desde donde se podría gatillar la formación de un movimiento social de rechazo a la dictadura, que ampliara las fronteras de los grupos militantes que conformaban los partidos de la UP (Moyano, 2010: 276).

Así para el MAPU, continua la autora, el interés por formar alianzas con otros sectores políticos no era un objetivo primordial en sí, estas se conseguían como consecuencia de "...la lucha cotidiana, las acciones de resistencia en los lugares de vivienda, de trabajo o de estudio donde esas alianzas se volvían reales, y se agrupaban a todos quienes aborrecían a la dictadura militar” (Moyano, 2010: 277). Desde una mirada similar en términos del proceso de renovación, se puede examinar el trabajo de Esteban Teo Valenzuela, Dios, Marx...y el MAPU. Desde un enfoque más insurreccional, encontramos el estudio de Nicolás Acevedo Arriaza sobre el nacimiento del brazo armado en MAPU-Lautaro. También con este foco analítico, Ivette Lozoya: "Chile: Violencia política y transición a la democracia. El MAPULautaro y la derrota de la vía revolucionaria en los 90".

De los intentos por rescatar la memoria de la resistencia socialista durante la dictadura, encontramos los trabajos de Eduardo Gutiérrez, Ciudad en las sombras, 
una historia no oficial del PS; Manuel Cortés, Yo patán. Memorias de un combatiente. El mérito de ambas propuestas no sólo radica en la visión de primera persona, sino que además intentan examinar el período a través de un diálogo historiográfico, examinando otras fuentes de estudio, en particular el trabajo de Gutiérrez. Anna M. Blasco Rovira y Vladimir Sierpe en "Militantismo y Resistencia socialista chilena entre 1973 y 1975: Historia de un sacrificio”, recogen las características de la primera resistencia socialista, esa que se funde con la sobrevivencia y la necesidad histórica de mantener al partido con vida. Los autores comentan de manera crítica las condiciones y las debilidades de esta incipiente noción de desobediencia que se buscaba instalar:

Las condiciones en las que se desarrolló la militancia durante los primeros años de la dictadura evidencian que la falta de preparación fue una de las causas principales que determinó la casi total aniquilación del Partido en muy poco tiempo. Los jóvenes socialistas que se integraron en la lucha clandestina no habían recibido en su mayoría una preparación adecuada, muchos no sabían ni manejar un arma y prácticamente todos desconocían las reglas básicas de la clandestinidad (Blasco Rovira y Sierpe, 2015: 125).

En uno de los esfuerzos más contundentes de examen del socialismo chileno, la investigación de Edison Ortiz sobre el partido desde el triunfo de la Unidad Popular hasta el primer gobierno de Michelle Bachelet, nos ofrece una mirada estructural a los ejes políticos y socioculturales del partido. Así, El socialismo chileno: de Allende a Bachelet, evidencia las enormes dificultades que tuvo que sortear una colectividad que venía de una tradición de participación institucional y que de la noche a la mañana se vio en un escenario de persecución y acorralamiento.

Sobre las complejidades y rearticulaciones orgánicas pueden revisarse los trabajos de Ricardo Yocelevsky, "El Partido Socialista de Chile bajo la dictadura militar". De Paul Drake, sobre todo el epílogo, Socialismo y populismo, Chile 19361973. Benny Pollack y Hernán Rosenkranz, Revolucionary Social Democracy. The Chilean Socialist Party. Juan Azócar Valdés, Prometamos jamás desertar. Apuntes para un memorial de la militancia socialista en la resistencia. Y el trabajo más reciente de Cristian Pérez, La vida con otro nombre. El Partido Socialista en la clandestinidad (1973-1979). Pérez reafirma nuevamente el panorama de las vicisitudes por las que tuvieron que pasar los militantes del partido de gobierno. El autor sostiene: "Entre tanto, dentro de Chile la vida de los militantes socialistas, como las de toda la izquierda, sufre una aguda mutación. La inmensa mayoría de los cuadros partidarios no tenía ninguna experiencia en hacer política en la clandestinidad, porque desde su origen la organización había funcionado en libertad" (Pérez, 2021: 81). 
Y es precisamente esa adaptación, uno de los rasgos más destacados del arte de resistir.

Estudios generales sobre la resistencia que abordan no solamente una organización en particular o balances historiográficos sobre el tema en cuestión, pueden verse en los trabajos de Víctor Figueroa Clark "The Forgotten History of the Chilean Transition: Armed Resistance Against Pinochet and US Policy towards Chile in The 1980"; Adriana Palomera Valenzuela y Pedro Rosas Aravena, "Presencia e impacto de las mujeres en la lucha armada contra la dictadura en la prensa oficialista. La Tercera 1978-1989"; Igor Goicovic Donoso, "Temas y debates en la historia de la violencia política en Chile". Goicovic propone una profundización historiográfica fundamentalmente en torno a la resistencia armada desarrollada durante el período dictatorial en donde según el autor

...es posible observar un creciente desarrollo de la violencia política, tanto en la frecuencia alcanzada por las acciones de esta naturaleza, como en los altos niveles de especialización operados por los grupos armados al objeto de desplegar dichas acciones. Ello se corresponde con un enunciado discursivo que legitimaba el uso de la violencia política contra la dictadura militar, como con un diseño estratégico y táctico que viabilizaba el uso de la misma como recurso de la acción política (Goicovic, 2014: 2).

Otros trabajos compilatorios que pueden revisarse son: Patricio Herrera, "La vía revolucionaria en Chile. Entre democracia, dictadura y transición (1965-1994)" y Francisco García Naranjo, Historias derrotadas. Oposición y obstinación de la guerrilla chilena (1965-1988).

En perspectiva de género, Cherie Zalaquett, en Chilenas en armas. Testimonios e historia de mujeres militares y guerrilleras subversivas, aborda la compleja relación entre la acción militar y el rol de género. Zalaquett nos propone

...una primera aproximación a una mirada crítica acerca de la presencia de la mujer chilena en organizaciones armadas desde la perspectiva de género. Pero, sobre todo, interrogar y problematizar la intervención femenina en el campo militar, un escenario de guerra o de guerrilla radicalmente masculinizado, que implica el ejercicio de la violencia y la agresividad cruentas hacia un enemigo mortal cuya destrucción debe procurarse" (Zalaquett, 2018: 9). 


\subsection{La vuelta de los generales argentinos}

Nuestra última detención temporal corresponde a la última dictadura instalada que respondía a las lógicas represivas antiizquierdistas. Junto con ser el último examen sobre el estado del arte, es también el más contundente y enriquecedor espacio de trabajo y análisis sobre el tema. La historiografía argentina se ha dedicado a explorar facetas nuevas y diversas sobre la historia reciente, siendo un espacio de referencia para dichos temas a nivel continental. No obstante, y tal como veremos reflejado en las conclusiones de historiadores e historiadoras, la resistencia a la última dictadura argentina tampoco evidencia este interés privilegiado, tal como lo ha sido el examen previo sobre los fenómenos de violencia política anteriores a 1976. En otras palabras, hubo en la disciplina historiográfica una motivación reconocible y entendible por examinar las complejidades y los efectos múltiples de la aparición de la violencia política, en particular las organizaciones político-militares durante el ciclo 1966-1976. Este contexto está enmarcado en la instalación de la dictadura de Juan Carlos Onganía, la derrota de la guerrilla boliviana del Che y la insurrección obrera y popular de Córdoba, conocida como el Cordobazo de 1969. La aparición y masificación de organizaciones guerrilleras tuvo como consecuencia para el análisis posterior un enfoque ampliamente centrado en este período, dejando en menor intensidad la preocupación por las izquierdas durante la instalación del Proceso de Reorganización Nacional, durante la Dictadura desde marzo de 1976. No obstante, los últimos estudios han retomado el interés por conocer la acción política de los actores históricos durante los siete años de ejercicio del autoritarismo militar, tomando en cuenta inicialmente el rol de los partidos políticos de izquierda, marxistas, y las organizaciones político-militares. También se examina la actuación de los sectores sindicales, el surgimiento de un potente movimiento de defensa de los DD.HH., como así también otras expresiones de resistencia al régimen imperante, como la resistencia cultural.

Una mirada general sobre el tránsito de las organizaciones políticas puede verse en el trabajo de Gabriela Águila, "La izquierda argentina, entre la dictadura y la transición democrática: notas para su estudio". La autora recalca uno de los elementos antes mencionado en relación al desbalance sobre los estudios temáticos. Águila comenta que

...a pesar de los avances en la historiografía del pasado reciente argentino que se registraron en estos últimos quince años (Águila et. al.), todavía persisten importantes vacíos en la construcción de conocimiento sobre el último medio siglo de la historia argentina que requieren ser abordados. Ejemplo de ello es el estudio de las 
izquierdas, ampliamente analizadas en todas sus vertientes y matices para la primera mitad del siglo XX y sobre todo para las décadas que median entre 1955 y 1975 y prácticamente ignoradas para el período abierto por el golpe de estado de 1976 (Águila, 2019: 278).

Precisamente con esa intencionalidad, la historiadora ha trabajado en dilucidar las señales y los comportamientos de una serie de acciones que integran esta acción resistente. Una profundización sobre estos modos, de la misma autora, pueden revisarse en "Violencia política, represión y actitudes sociales en la historia argentina reciente". Otro de los trabajos que intenta completar el panorama de las izquierdas durante el período represivo es la investigación de Ignacio Moretti, "Tiempo de verdugos: Los partidos de izquierda ante la instauración de la última dictadura cívico-militar argentina”. Moretti desarrolla un cuadro amplio en donde es posible observar y clasificar las reacciones de la militancia de izquierda, tanto de los pequeños partidos como de los más históricos, frente a las disposiciones autoritarias. El autor recalca que

Todos los partidos de izquierda aquí abordados, Partido Comunista (PC), Partido Comunista Revolucionario (PCR), Política Obrera (PO), Partido Socialista de los Trabajadores (PST), Frente Izquierda Popular (FIP) y Partido Revolucionario de los Trabajadores-Ejército Revolucionario del Pueblo (PRT-ERP), con sus particularidades y heterogeneidades, fueron objeto de la ilegalización, acechanza, represión, desaparición física y terror; merced a lo cual reorientaron su actividad política y militante a esferas subterráneas y hacia el movimiento estudiantil, el nacimiento de movimientos de derechos humanos y el quehacer con los trabajadores, tratando de avivar y agitar desde estas bases la oposición a la dictadura (Moretti, 2016: 26).

Si bien Moretti encuadra en un sólo casillero a toda la izquierda, es reconocida la actitud de los militares hacia el Partido Comunista Argentino. Gabriela Águila en "El partido comunista argentino entre la dictadura y la transición democrática (1976-1986)" realiza un balance crítico del accionar de los comunistas evidenciando al respecto el contraste entre las otras organizaciones de la izquierda. Águila señala que “...el partido siguió siendo legal, mantuvo la estructura organizativa y transitó esos años con menos dificultades. Por su parte, su actuación ha sido analizada muy críticamente, en tanto la línea que asumió frente al régimen militar fue calificada como moderada, complaciente e incluso de colaboración" (Águila, 2008: 58).

Esta visión también puede identificarse en parte con los otros actores del espectro político, donde según la autora, existió una ausencia de críticas abiertas 
hacia los militares, en donde es posible observar un cierto grado de aceptación a la nueva situación política de restauración del orden y la paz social.

En uno de los estudios más profundos sobre el comunismo argentino, Natalia Casola, EI PC argentino y la dictadura militar. Militancia, estrategia política y represión estatal, comparte la visión de Águila, y ahonda no sólo en las líneas estratégicas del partido, sino que también se sumerge en identificar la fisonomía de la militancia durante el período. Así, llega a la conclusión de que frente a las disposiciones del partido, los comunistas se adaptaron a esta "forma de resistir". Casola señala

...ni antes ni después la incomodidad con la línea se transformó en fuente de explosiones internas. Por el contrario, la mayoría de la militancia, con algunas excepciones, se disciplinó a los mandatos partidarios, obedeció reglas y reprodujo la política tal cual era transmitida en los informes centrales. A lo largo y ancho del territorio, los y las militantes comunistas intentaron conservar sus rutinas habituales y llevar adelante algún nivel de vida partidaria (Casola, 2015: 144).

María Florencia Osuna analiza a otro de los actores políticos con cierta presencia en el panorama argentino, y que no había tenido la ocupación debida. El estudio más consistente sobre el trotskismo tiene un capítulo bajo el contexto represivo en "De la Revolución socialista a la revolución democrática. Las prácticas políticas del Partido Socialista de los Trabajadores/Movimiento al Socialismo durante la última dictadura (1976-1983)". Uno de los objetivos de la autora es llenar el vacío sobre este tema, y en particular lo que Osuna apunta, observar la fisonomía orgánica que adoptaron los partidos, en este caso el PST. La historiadora señala que

La mayor parte de las producciones académicas citadas no da cuenta, por ejemplo, de las formas organizativas y actividades desarrolladas por las organizaciones en el marco de un régimen basado en el terrorismo de Estado. Si bien señalan las lecturas de los partidos sobre el gobierno de Videla, no analizan la compleja dinámica de adhesión y resistencia que atravesaba a grupos políticos que eran parte constitutiva del blanco del dispositivo represivo (Osuna, 2015: 14).

Una de las interesantes diferenciaciones que señala la autora, es sobre la intencionalidad de la estructura clandestina, en donde se observan disimiles propósitos. En el caso de las organizaciones guerrilleras, este entramado oculto, tenía un objetivo ofensivo de derrotar al enemigo, en cambio, en los grupos no armados, la estructura clandestina funcionaba como marco de protección frente al accionar represivo, y como posibilidad de continuar con la vida militante (Osuna, 
2015: 46). Estas experiencias, señala la autora, estaban en parte inspiradas en las historias de resistencia del Partido Comunista Alemán, en contra del régimen nazi.

Tal como hemos observado, el accionar desgastado de las organizaciones guerrilleras una vez perpetrado el golpe de Jorge Rafael Videla, decantó en una mínima presencia activa durante gran parte de la dictadura. Esto se refleja en la preocupación historiográfica menos profunda sobre estas orgánicas durante el período de clandestinidad. Vera Carnovale ahonda solamente en el prólogo de uno de sus textos más renombrados sobre el PRT. Si bien se destaca la intención inicial de luchar por derrotar al nuevo régimen y se observaron durante los primeros meses acciones destinadas hacia ese foco, las disposiciones de la estructura del PRT de salir al exilio, y la consecuente división en 1978 de la organización, terminaron por diluir el rol resistente, por lo menos en forma orgánica. Estas conclusiones pueden revisarse en Vera Carnovale, Los combatientes. Historia del PRT-ERP. Similar visión sobre la debilidad de esta organización puede verse en Por las sendas argentinas. El PRT-ERP, la guerrilla marxista, del historiador Pablo Pozzi. El autor recalca:

Los militantes del PRT-ERP se lanzaron a la lucha contra el golpe militar redoblando sus actividades militares y agitativas. Sin embargo, la organización no estaba preparada para esto...Lejos de fundirse con las masas para enfrentar a la represión, el PRT-ERP se lanzó hacia adelante exponiendo aún más a sus militantes y evidenciando un voluntarismo notable (Pozzi, 2004: 374).

La dirección decidió por medidas de seguridad salir al exterior, quedando en el país sólo algunos cuadros que resistieron con las mínimas condiciones los embates represivos. Ahondando sobre este último rasgo, Julio Santucho en Los últimos guevaristas. La guerrilla marxista en la Argentina, comenta que el grueso del accionar resistente de la izquierda armada, se trasladó hacia el extranjero, y desde allí, desplegaron las acciones de colaboración y solidaridad. Santucho sostiene que "muchos militantes políticos, activistas sindicales o intelectuales comprometidos con la voluntad de cambio de la generación de los 70' se vieron obligados al exilio para preservar sus vidas...Esos hombres y esas mujeres siguieron su lucha en el exterior" (Santucho, 2004: 244).

Sobre el rol de los Montoneros durante el período en estudio puede verse el clásico trabajo de Richard Gillespie, Los soldados de Perón. Historia crítica sobre los Montoneros. Al igual que el resto de las organizaciones armadas, las disposiciones combativas iniciales no lograron mantenerse durante todo el periodo. Si bien como recalca Gillespie, existió un voluntarismo alojado en la experiencia armada, en dónde “...el papel del Ejercito Montonero era ahora el de detener los avances del enemigo y hacer lo posible para que las masas se reorganizaran y resistiesen. Traducido en 
términos prácticos, ello suponía el lanzamiento de ataques simples pero eficaces contra el centro de gravedad del enemigo" (Gillespie, 2011: 357). Tal como sostiene el mismo autor más adelante, esa experiencia desarrollada previamente fue infructuosa a la hora de enfrentar a las Fuerzas Armadas, volcándose entonces los Montoneros en un último acto de resistencia, en apoyo hacia las primeras señales de una oposición sindical.

Sobre este tema, uno de los principales estudios desarrollados es, de Pablo Pozzi, Oposición obrera a la dictadura (1976-1982). Pozzi intenta desmitificar la imagen de un sector inmovilizado y silenciado por las disposiciones dictatoriales, y más bien mostrar un panorama de readecuación y recomposición de las prácticas sindicales, desarrolladas por uno de los movimientos más fuertes y centrales de la historia argentina. Al respecto, Pozzi sostiene que

...un análisis un poco más profundo muestra que la activada del movimiento obrero es muchísimo más compleja combinando, de acuerdo a condiciones cambiantes, actividad pública y subterránea. De hecho, es poco probable que un movimiento obrero en actitud de ofensiva y altamente movilizado, que viene cuestionando al sistema y a su representación sindical, caiga repentinamente en el inmovilismo, aun tomando en cuenta la represión (Pozzi, 1988: 25).

Estas prácticas subterráneas, esas acciones pasivas, esa resistencia gris, es lo que precisamente enriquece el análisis sobre este fenómeno, demostrado en este caso, en los modos readaptados del quehacer sindical.

Para una profundización sobre estas orgánicas, puede verse el trabajo de Daniel Dicósimo, "La resistencia de los trabajadores a la última dictadura militar. Un aporte a su conceptualización", que no solamente describe el accionar de estos actores, sino que realiza un ejercicio también epistemológico sobre la naturaleza de dicho concepto. Al respecto Dicósimo se propone "repensar el concepto de 'resistencia' como sinónimo de conductas no consensuales de los trabajadores durante el período de la última dictadura cívico-militar en la Argentina, tanto respecto a las políticas económicas y laborales de la misma, como a las directivas patronales en el lugar de trabajo" (Dicósimo, 2015: 71).

El interés historiográfico sobre el movimiento de trabajadores es amplio y consistente, al respecto pueden revisarse también "Experiencias de lucha y resistencia obrera durante la última dictadura militar: el Gran Rosario 1976-78” de Andrés Carminati; "Conflicto Social y régimen militar. La resistencia obrera en Argentina” de Ricardo Falcón; "Las luchas sindicales contra el Proceso. 1976-1980: Cinco Años de Resistencia”, de Gonzalo Chaves, entre otros.

El fuerte impacto de la represión en Argentina, no sólo cualitativamente, sino que también en términos cuantitativos, generó rápidamente el desarrollo de un 
fuerte movimiento de protección hacia los Derechos Humanos. Sobre este tema puede verse el trabajo de Luciano Alonso, "Las luchas pro derechos humanos en Argentina: de la resistencia antidictatorial a la dispersión del movimiento social". Alonso refuerza la tesis sobre la diversificación en torno a la comprensión del fenómeno resistente. Al respecto el autor plantea: "Erigido en símbolo de la resistencia, el movimiento social había logrado una importante centralidad y efecto, pese a ser integrado por relativamente pocas personas en comparación con otros agentes colectivos y a estar muy desigualmente distribuido al interior del territorio nacional" (Alonso, 2013: 106).

La génesis de este colectivo incipiente, que finalmente se encumbró como un fuerte movimiento a nivel nacional y con repercusiones internacionales, muestra la persistencia de la resistencia y el matiz silencioso de su accionar. Sobre el mismo tema encontramos el trabajo de Mauricio Fernández Picolo, "Violencia institucionalizada, Derechos Humanos en Argentina". Fernández Picolo rescata el rol de familiares y amigos de las víctimas, que sistemáticamente van erigiendo no sólo una orgánica de colaboración, sino que se convierten en espacios simbólicos de desobediencia. Al respecto el autor comenta: "En estos grupos hay dos actitudes frecuentes, por un lado, una práctica de la solidaridad social y una apelación permanente a ella y, por otro, un profundo reclamo de respeto de la pluralidad política y del derecho a disentir" (Fernández Picolo, 2000: 383). Para el autor, la lucha por los Derechos Humanos se convierte en la acción política de resistencia más significativa.

La resistencia cultural se transformó en uno de los elementos más reconocibles del fenómeno de oposición al régimen dictatorial argentino. El bagaje cultural vinculado a los espacios urbanos jugó un rol central en la conformación de un entramado de robustecimiento de distintas expresiones que surgieron y se adaptaron al espacio subterráneo. Mariana Eva Cerviño, en "Las revistas culturales como espacios de resistencia en la última dictadura militar argentina. De El Expreso Imaginario a El Porteño, 1976-1983", se aproxima al estudio de determinados medios escritos durante el escenario autoritario, espacios que se transformaron en centros de intercambio de experiencias, atrevimientos y disputas hegemónicas de un saber. La autora refuerza esta noción al señalar que dichas expresiones fueron una fusión entre las prácticas antiguas de experimentación y vanguardia, propia de las década de los sesenta, y por otro camino de expresión: “....algunos espacios de producción de bienes simbólicos pudieron articular en su entorno grupos identificados con códigos estéticos alternativos y eventualmente opositores a todo lo que se percibiera como parte de la cultura dominante en el período" (Cerviño, 2012: 105). Surge la doble necesidad del rol rupturista de la expresión artística, sobre todo en contextos represivos, donde adquiere un cariz liberador por excelencia. En la misma línea de conexión, puede verse el trabajo de Federico Iglesias sobre los 
creadores de estos relatos. En "Escritores, dictadura y resistencia: un estudio sobre la revista El Ornitorrinco 1977-1983”, Iglesias articula el rol de los escritores durante el período autoritario, entendiendo que los escritores en contextos dictatoriales reescriben su rol con la política, asumiendo nuevos lazos, señales simbólicas de resistencia y compromiso. Aparecen así, nuevas motivaciones y heterogéneas formas de expresión creativa.

En otro de los espacios de resistencia, quizás uno de los más ocultos, Santiago Garaño se aproxima al fenómeno del encierro político de mujeres bajo la dictadura. Entender los sentidos y la simbología que rodea al accionar de las encarceladas, como parte también de una acción política, es uno de los objetivos de la reflexión del autor. "Romper la vidriera, para que se vea la trastienda”. Sentidos, valores morales y prácticas de "resistencia" entre las presas políticas de la cárcel de Villa Devoto durante la última dictadura militar argentina (1976-1983)”, se adentra en los subterráneos más significativos de las actitudes de las presas militantes, ordenando el panorama de la resistencia, no sólo como actitud contestataria, sino que también como representación. El autor destaca que

La "resistencia" como valor moral se revela altamente polisémico y dinámico y debe ser analizado en el marco de sus transformaciones a lo largo del proceso social e histórico y a la luz de los contextos institucionales: no era lo mismo "resistir" a la tortura en los centros clandestinos de detención que "resistir" en la cárcel; no "resistieron" de la misma forma las detenidas que militaban en el PRT y las de Montoneros; y a su vez, en la cárcel, la "resistencia" no fue un concepto homogéneo, sino que se fue modificando frente a los regímenes aplicados. En este sentido, la "resistencia" ha operado, por un lado, como medio y fundamento de sus acciones y, por el otro, les ha permitido posicionarse y disputar entre sí (Garaño, 2010: 118).

Destacamos la utilización de la noción polisémica de la resistencia, ya que refuerza la intención inicial de este recorrido historiográfico, que pretende observar el fenómeno desde distintas dimensiones.

\section{Balance final}

Uno de los primeros elementos que resaltan de esta revisión, es la distancia entre los panoramas historiográficos locales. En un punto del abanico se observan las realidades bolivianas y paraguayas con un menor desarrollo en volumen y cobertura de las temáticas. Desde el otro lado, la historiografía argentina y chilena han avanzado considerablemente en la revisión de diversos problemas históricos. Una de las razones que se pueden esgrimir, tiene que ver con los avances, aunque 
siguen siendo insuficientes, en materia de reparación y justicia en torno a las violaciones a los Derechos Humanos. Estos procesos reparatorios fueron acompañados en algunos casos con la instalación de una institucionalidad que dio paso a la creación de archivos, clasificación y detección de fuentes y repositorios sobre la vida política durante los años represivos. En otro ámbito, se puede aventurar también como posible explicación sobre las distancias historiográficas, el rol de los centros de estudios, universidades y ONGs, en el impulso y estímulo para el avance en conocer aspectos de la Historia Reciente de los distintos países. El caso argentino es muy ejemplificador en este sentido, en donde se genera un circuito de reproducción y desarrollo de la historiografía, en donde confluyen editoriales, espacios de debate científico y los distintos centros de estudios.

Un segundo elemento dice relación con la amplitud con que se ha tratado el tema de la resistencia, saliendo de los márgenes más tradicionales vinculados generalmente al estudio de la lucha armada. Si bien este es un campo de estudio fructífero y en desarrollo, la heterogeneidad del concepto, lo polisémico, nos invita a observar las distintas vertientes del acto de resistir en contextos autoritarios. Esta obertura, es un ejercicio que ha realizado no sólo la disciplina histórica, como hemos observado, sino que se convierte también en un uso testimonial de quienes han protagonizado estos acontecimientos. Así, el resistir está vinculado no solamente a la organización política clandestina, también es un acto teatral en medio de las prohibiciones, la edición de un boletín o la creación musical en los subterráneos de la sociedad.

Un último elemento que nos parece interesante recalcar, es que los acentos historiográficos han estado marcados por la naturaleza misma de las sociedades que las protagonizan, y dan cuenta de los principales elementos identitarios de esos escenarios. En otras palabras, observamos el foco mayoritario de estudio de las comunidades indígenas bajo los contextos autoritarios paraguayos y bolivianos, un mayor rescate del rol de los obreros en Argentina, Brasil y Bolivia, un peso intencionado en el desenlace de las organizaciones de izquierda bajo la dictadura chilena, y un interés en conocer el rol de los militantes afrodescendientes brasileños en el contexto autoritario. Esto que pareciera ser algo elemental, nos permite observar, como contraparte, los nichos o espacios poco explorados sobre la resistencia en las distintas sociedades conosureñas. Surge la interrogante en relación a conocer sobre las comunidades indígenas en el Chile dictatorial, o la intelectualidad boliviana frente al gobierno de Banzer, entre otros acentos en que sería interesante adentrarse. 


\section{Bibliografía}

Acevedo Arriaza, N. (2014): MAPU-Lautaro. Concepción, Ediciones Escaparate.

Águila, G. (2008): "El partido comunista argentino entre la dictadura y la transición democrática (1976-1986)”, Revista Historia Actual, 6(6), pp. 57-69.

Águila, G. (2015): "Violencia política, represión y actitudes sociales en la historia argentina reciente" en Pensar con la Historia desde el siglo XXI. XII Congreso de la Asociación de Historia Contemporánea, Universidad Autónoma de Madrid (ponencia).

Águila, G. (2019): "La izquierda argentina, entre la dictadura y la transición democrática: notas para su estudio", Revista Historia Social y de las Mentalidades, 23(2), pp. 277-304.

Alonso, L. (2013): "Las luchas pro Derechos Humanos en Argentina: de la resistencia antidictatorial a la dispersión del movimiento social", Observatorio Latinoamericano $\mathrm{N}^{\circ} 12$, dossier Argentina: 30 años de democracia.

Álvarez, R. (2001): “Clandestinos 1973-1990. Entre prohibiciones públicas y resistencias privadas", en C. Gazmuri y R. Sagredo, Historia de la vida privada en Chile, Tomo III. Santiago, Taurus.

Álvarez, R. (2003): Desde las sombras. Una Historia de la clandestinidad comunista (1973-1980). Santiago, LOM ediciones.

Álvarez, R. (2011): Arriba los pobres del mundo. Cultura e identidad política del Partido Comunista de Chile entre democracia y dictadura. Santiago, LOM ediciones.

Álvarez, R. (2014): "Las Juventudes Comunistas de Chile y el movimiento estudiantil secundario: un caso de radicalización política de masas (1983-1988)", en R. Álvarez y M. Loyola, Un trébol de cuatro hojas: Las Juventudes Comunistas de Chile en el siglo XX, Santiago, Ariadna Editores.

Álvarez, R. (2017): "Historia e historiografía del Comunismo: debates y nuevos enfoques", Revista de Historia Social y de las Mentalidades, 21(2), pp. 11-29.

Alves Pereira, P. (2017): "La resistencia cotidiana de los Aché durante el régimen cívico-militar de Alfredo Stroessner en el Paraguay”, Religación, Revista de Ciencias Sociales y Humanidades, 2(7), pp. 112-125. 
Alzugarat, A. (2007): Trincheras de papel. Dictadura y literatura carcelaria en Uruguay. Uruguay, Ediciones Trilce.

Amorós, M. (2008): La memoria rebelde. Testimonios sobre el exterminio del MIR de Pisagua a Malloco. Concepción, Ediciones Escaparate.

Aquino, M.A. (1999): Censura, Imprensa, Estado Autoritário (1968-1978). Brasil, EDUSC.

Arancibia Ortiz, E. (2015): Las milicias de la resistencia popular. El MIR y la lucha social armada en dictadura 1979-1984. Concepción, Ediciones Escaparate.

Azócar Valdés, J. (2007): Prometamos jamás desertar. Apuntes para un memorial de la militancia socialista en la resistencia. Santiago, Memoria y Futuro.

Blasco Rovira, A. M. y V. Sierpe (2015): "Militantismo y resistencia socialista chilena entre 1973 y 1975: Historia de un sacrificio", Revista de Historia Social y de las Mentalidades, 19(1), pp. 107-128.

Boccia, A. (2010): "Represión política y género en la dictadura paraguaya", en J. M. Pedro y C. Scheibe Wolff, Gênero, feminismos e ditaduras no Cone Sul. Florianópolis, Ed. Mulheres.

Bravo Vargas, V. (2010): ¡Con la razón y la fuerza, venceremos! La rebelión popular y la subjetividad comunista en los $80^{\prime}$. Santiago, Ariadna Ediciones.

Carminati, A. (2012): "Experiencias de lucha y resistencia obrera durante la última dictadura militar: el gran rosario 1976-78”, Avances del Cesor, 9(9), pp. 33-53.

Carnovale, V. (2011): Los combatientes. Historia del PRT-ERP. Buenos Aires, Siglo XXI.

Carrera, J. M. (2013): Somos tranquilos pero nunca tanto.... Santiago, Ceibo ediciones.

Casola, N. (2015): El PC argentino y la dictadura militar. Militancia, estrategia política y represión estatal. Buenos Aires, Imago Mundi.

Caygill, H. (2016): De la Resistencia. Una filosofía del desafío. España, Armaenia Editorial. 
Cerviño, M. E. (2012): "Las revistas culturales como espacios de resistencia en la última dictadura militar argentina. De El Expreso Imaginario a El Porteño, 19761983”, Desafíos, 24(2), pp. 105-134.

Cháves, G. (1983): Las luchas sindicales contra el Proceso. 1976-1980: Cinco Años de Resistencia. Buenos Aires, La Causa.

Cortés, M. (2015): Yo patán. Memorias de un combatiente. Santiago, Ceibo ediciones.

De Freitas Silva, N. (2016): "Desmistificando a "Resistência democrática" a ditadura civil-militar (1964-1985)”, Revista Dia-logos, 10(1), pp. 60-69.

Dicósimo, D. (2015): "La resistencia de los trabajadores a la última dictadura militar. Un aporte a su conceptualización”, Avances del Cesor, 12(13), pp. 71-93.

Drake, P. (1992): Socialismo y populismo, Chile 1936-1973. Valparaíso, Ediciones Universitarias de Valparaíso.

Falcón, R. (1982): "Conflicto Social y régimen militar. La resistencia obrera en Argentina", en B. Galitelli y A. Thompson, Sindicalismo y regímenes militares en Argentina y Chile. Amsterdam, CEDLA.

Fernández Picolo, M. (2000): "Violencia institucionalizada, Derechos Humanos y resistencia en Argentina", en S. Devalle, Poder y cultura de la violencia, El Colegio de México.

Figueroa Clark, V. (2015) "The Forgotten History of the Chilean Transition: Armed Resistance Against Pinochet and US Policy towards Chile in The 1980", Journal of Latin American Studies, 3(47), pp. 491-520.

Galiana I Cano, V. (2018): "El triunfo del posibilismo: el MLN-Tupamaros entre la revolución armada y la integración democrática (1970-1989)”, Naveg@mérica, Revista electrónica editada por la Asociación Española de Americanistas, 21, pp. 117.

Garaño, S. (2010): “'Romper la vidriera, para que se vea la trastienda'. Sentidos, valores morales y prácticas de 'resistencia' entre las presas políticas de la cárcel de Villa Devoto durante la última dictadura militar argentina (1976-1983)", Historia critica, 40, pp. 98-120. 
García Naranjo, F. (1997): Historias derrotadas. Oposición y obstinación de la guerrilla chilena (1965-1988). México, Universidad Michoacana de San Nicolás de Hidalgo.

Gillespie, R. (2011): Los soldados de Perón. Historia crítica sobre los Montoneros. Buenos Aires, Ed Sudamericana.

Goicovic Donoso, I. (2014): “Temas y debates en la historia de la violencia política en Chile". Contenciosa, 2(3), pp. 1-16.

Goicovic Donoso, I. (2016): Trabajadores al poder. El Movimiento de izquierda revolucionaria y el proyecto revolucionario en Chile. 1965-1994. Concepción, Ediciones Escaparate.

Green J. N. y Quinalha, R. (2014) Ditadura e Homossexualidades; Repressão, Resistência e a busca da Verdade. Rio de Janeiro, Edufscar.

Gutiérrez, E. (2003): Ciudad en las sombras, una historia no oficial del PS. Santiago, Colección memoria histórica.

Hernández Norambuena, M. (2016): Un paso al frente. Habla el comandante Ramiro del FPMR. Santiago, Ceibo ediciones.

Herrera, P. (2014): "La vía revolucionaria en Chile. Entre democracia, dictadura y transición (1965-1994)", en VV.AA., El estudio de las luchas revolucionarias en América Latina (1959-1996) Estado de la cuestión. El Colegio de Michoacán, Universidad de Santiago de Compostela.

Horbach, A. L. (2020): “Autoria e resitencia negra na ditadura civil-militar no Brasil”, Nau Literária, 17(1), pp. 158-176.

Iglesias, F. (2019): Escritores, dictadura y resistencia: un estudio sobre la revista El Ornitorrinco 1977-1983. Universidad Nacional de General Sarmiento, Universidad Nacional de La Plata, Universidad Nacional de Misiones.

Jelin, E. (2001): "Exclusión, memoria y luchas políticas”, en Estudios Latinoamericanos sobre cultura y transformaciones sociales en tiempos de Globalización. CLACSO, Consejo Latinoamericano de Ciencias Sociales.

Lora, G. (1978): Historia del POR. Contribución a la Historia política de Bolivia. La Paz, Ediciones Isla. 
Lora, G. (1980): Historia del movimiento obrero boliviano. El proletariado en el proceso político, 1952-1980. Tomo VI. Bolivia, Ediciones Masas.

Lozoya, I. (2012): "Chile: Violencia política y transición a la democracia. El MAPULautaro y la derrota de la vía revolucionaria en los 90", en P. Pozzi y C. Pérez, Historia oral e historia política. Izquierda y lucha armada en América Latina, 19601990. Santiago, LOM Ediciones.

Margiolakis, E. (2011): “Cultura de la resistencia, dictadura y postdictadura”, en VI Jornadas de Jóvenes Investigadores. Buenos Aires, Instituto de Investigaciones Gino Germani, Facultad de Ciencias Sociales, Universidad de Buenos Aires (ponencia).

Moreira Leite, P. (2016): A Mulher que era o general da Casa. Histórias da resistência civil á ditadura. Brasil, Arquipelago editorial.

Moretti, I. (2016): "Tiempo de verdugos. Los partidos de izquierda ante la instauración de la última dictadura cívico-militar argentina", Revista de la Red de Intercátedras de Historia de América Latina Contemporánea, 3(5), pp. 24-39.

Moyano, C. (2010): El MAPU durante la dictadura. Saberes y prácticas políticas para una microhistoria de la renovación socialista en Chile 1973-1989. Santiago, Ediciones Universidad Alberto Hurtado.

Nercesián, I. (2005): “Una aproximación a la izquierda brasileña de los años sesenta. Partidos y organizaciones armadas", Revista electrónica de estudios latinoamericanos, 3(10), pp. 27-40.

Ortiz, E. (2007): El Socialismo Chileno, de Allende a Bachelet, (1973-2005). Santiago, FIADELSO-PLA.

Osuna, M. F. (2015): De la Revolución socialista a la revolución democrática. Las prácticas políticas del Partido Socialista de los Trabajadores/Movimiento al Socialismo durante la última dictadura (1976-1983). Universidad Nacional de La Plata. Facultad de Humanidades y Ciencias de la Educación; Universidad Nacional de Misiones.

Palma, J.A. (2012): El MIR y su opción por la guerra popular. Concepción, Ediciones Escaparate. 
Palomera Valenzuela, A. y P. Rosas Aravena (2018): "Presencia e impacto de las mujeres en la lucha armada contra la dictadura en la prensa oficialista. La Tercera 1978-1989", Cuadernos de Historia, 48, pp. 89-125.

Peña, J. C. (2007): Los fusileros. Santiago, Debate.

Pérez, C. (2003): "Historia del MIR. Si quieren guerra, guerra tendrán", Estudios Públicos, 91, pp. 5-44.

Pérez, C. (2013): "La Política de Rebelión Popular de Masas y el Movimiento Democrático Popular (MDP): Una mirada a la política de alianzas del Partido Comunista de Chile bajo Pinochet, 1980-1988”, Pacarina del Sur, 5(17).

Pérez, C. (2021): La vida con otro nombre. El Partido Socialista en la clandestinidad (1973-1979). Santiago, Catalonia.

Pollack, B. y Rosenkranz, H. (1986): Revolucionary Social Democracy. The Chilean Socialist Party. London, Palgrave Macmillan.

Pozzi, P. (2004): Por las sendas argentinas. El PRT-ERP, la guerrilla marxista. Buenos Aires, Imago Mundi.

Ridenti, M. (2014): "As oposições à ditadura: resistência e integração" en D. Aarao Reis, M. Ridenti y R. Patto Sa Motta, A ditadura que mudou o Brasil: 50 anos do golpe de 1964. Brasil, Zahar.

Rivera Cusicanqui, S. (2010): Oprimidos pero no vencidos. Luchas del campesinado aymara y quechwa 1900-1980. La Paz, Ediciones La mirada salvaje.

Rodríguez Ostria, G. (2017): "Guerrilla, armas y campesinado: del Ejército de Liberación Nacional (ELN) al Partido Revolucionario de los Trabajadores en Bolivia (PRTB) (1967-1977)", en VV.AA., Los partidos de izquierda ante la cuestión indígena, 1920-1977. Bolivia, CIS.

Rojas Flores, J. (2000): “Historia, historiadores y comunistas chilenos", en M. Loyola y J. Rojas (compiladores), Por un rojo amanecer. Hacia una historia de los comunistas chilenos. Santiago, CENDA.

Rojas Núñez, L (2018): Carrizal. Las armas del PCch. Un recodo en el camino. Santiago, LOM ediciones. 
Rojas Núñez, L. (2011): De la rebelión popular a la sublevación imaginada. Santiago, LOM ediciones.

Salinas, S. (2014): El Tres Letras. Historia y contexto del Movimiento de Izquierda Revolucionaria. Santiago, RIL editores.

Santucho, J. (2004): Los últimos guevaristas. La guerrilla marxista en la Argentina. Argentina, Ediciones B.

Silva Hidalgo, R. (2011): Resistentes y Clandestinos. La violencia política del MIR en la dictadura profunda, 1978-1982). Concepción, Ediciones Escaparate.

Soto Vergara, J. (2019): El FPMR y el batallón 7. Santiago, RIL editores.

Telo, F. (2019): "Campesinos, emociones y tentativas de resistencia armada a la dictadura empresarial-militar de Brasil”, Polis, 53, pp. 1-17.

Torres Montenegro, A. (2014): "Dictadura en Brasil (1964-1985) La militancia política, el encarcelamiento y la tortura”, Confluenze, 6(2), pp. 167-200.

Tricot, T. (2015): Un sociólogo en el FPMR. Santiago, Ceibo ediciones.

Valenzuela, E. T. (2014): Dios, Marx...y el MAPU. Santiago, LOM ediciones.

Vera Quiroz, A. (2011): Tortura, clandestinidad y dictadura. Una mirada desde la militancia mirista, 1982-1984. Concepción, Ediciones Escaparate.

Verdueta, J. M. (2017): "El Movimiento Universitario frente a la dictadura en Bolivia. El caso de San Andrés del 71”, Revista Historia, 35, pp. 1-20.

Vidal, H. (1995): El Tabú del conflicto armado en Chile. Santiago, Mosquito editores.

VVAA (2004): "La resistencia armada a la dictadura de Stroessner", NovaPolis, 8, pp. $4-26$.

Whitehead, L. (1980): "Sobre el radicalismo de los trabajadores mineros de Bolivia", Revista Mexicana de Sociología, 42(4), pp. 1465-1496.

Yocelevsky, R. (1986): "El Partido Socialista de Chile bajo la dictadura militar", Revista Foro Internacional, 27(105), pp. 102-131. 
Zalaquett, Ch. (2018): Chilenas en armas. Testimonios e historia de mujeres militares y guerrilleras subversivas. Santiago, Catalonia.

Fecha de recepción: 22 de abril de 2021

Fecha de aceptación: 1 de julio de 2021 